\title{
Erratum: Superradiant and stimulated-superradiant emission in prebunched electron-beam radiators. I. Formulation \\ [Phys. Rev. ST Accel. Beams 8, 030701 (2005)]
}

\author{
A. Gover
}

(Received 31 October 2006; published 15 November 2006)

DOI: 10.1103/PhysRevSTAB.9.119901

PACS numbers: 41.60.Cr, 42.50.Fx, 41.60.- m, 52.59.-f, 99.10.Cd

An incorrect version of Fig. 7 appears online. The abscissa scale is erroneous.

The corrected version of Fig. 7 appears below. The conclusions are not affected by this error.

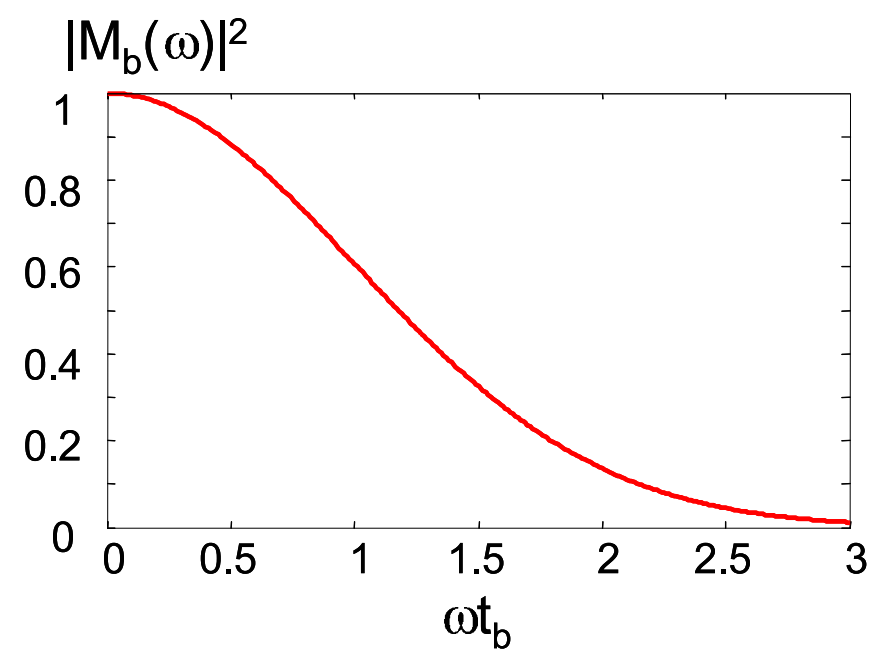

FIG. 7. (Color) The bunching form factor $\left|M_{b}(\omega)\right|^{2}=\exp \left(-\omega^{2} t_{b}^{2} / 2\right)$ for a Gaussian $e$-beam bunch distribution $f\left(t_{0}\right)=$ $\exp \left(-t_{0}^{2} / t_{b}^{2}\right) /\left(\sqrt{\pi} t_{b}\right)$. 